\title{
USING INDEX AND CUMULATIVE OVERLAY ANALYSES TO DETERMINE GEOTHERMAL POTENTIAL TARGETS IN DAMAVAND REGION
}

\author{
A. R. Rahmati ${ }^{1}$, A. Moradzadeh ${ }^{1, *}$, P. Pahlavani ${ }^{2}$, M. R. Rahmani ${ }^{3}$ \\ ${ }^{1}$ School of Mining Engineering, College of Engineering, University of Tehran, Tehran, Iran - (alireza.rahmati@ut.ac.ir; \\ a_moradzadeh@ut.ac.ir) \\ ${ }^{2}$ School of Surveying and Geospatial Engineering, College of Engineering, University of Tehran, Tehran, Iran - (pahlavani@ut.ac.ir) \\ ${ }^{3}$ Department of Renewable energy, Ministry of energy, Tehran, Iran - (rhisuna@ yahoo.com)
}

Commission VI, WG VI/4

KEY WORDS: Geothermal, Damavand, GIS, Integration, Cumulative Overlay, Index Overlay

\begin{abstract}
:
The Damavand region is located in the north of Iran and north-eastern of Tehran. In the present study, geothermal favorability map in this region has been prepared using two methods of data integration in the geographic information system (GIS) environment. The purpose of this study is to introduce the areas with high potential of geothermal field in Damavand region for subsequent exploratory program. For this purpose, at first, necessary information layers identified and studied and then were processed. The 13 layers were identified and collected and integration with two cumulative and weighted index overlay methods and compared. After a survey of experts, the weights used in the weighted index overlay method were obtained from the Fuzzy /Ahp method. In the result of cumulative overlay method, south and southeast of Damavand volcano are favorable area for geothermal field but the result of the weighted index overlay method indicates the high potential of the southeastern region of Damavand. Comparing the results with gradient and thermal flux from drilling by the ENEL Italian Company, indicate the accuracy and precision of the obtained results.
\end{abstract}

\section{INTRODUCTION}

A great deal of attention has been focused on renewable energy sources, with large sums of money allocated to the exploration of geothermal energy sources. Being applicable in electricity and heat production, geothermal energy sources can be targeted using geographic information systems (GIS) (Yousefi, 2010). GIS and remote sensing provide different tools for importing, analyzing and displaying spatially related data from different formats and sources (Delavar, 2004; Pahlavani et al., 2006; Pahlavani et al., 2017; Bahari et al., 2014; Bigdeli, 2013).

This study seeks to delineate geothermal targets of Damavand region, located in the northern Iran. This is an E-W trending composite volcano, andesitic in composition, partially affected by the accumulation volcano-sedimentary sequence (Davidson et al, 2004). This region abounds with the presence of several hot springs, including those found in Larijan, Baidjan and AbAsk. The exploration of these sources commenced with the investigations of Enel Company, yielded in the recognition of a potential zone comprising an area of $5,500 \mathrm{~km}^{2}$. There are Hot Springs, geophysical, geological, remote sensing and structural data, which can be used in a GIS system to target geothermal sources (Nouraliee et al, 2010).

\section{GEOLOGICAL SETTING}

Covered by masses of andesitic to basaltic lava (Figure 1), Damavand mountains are a part of the Alpine -Himalayan belt. There is a consensus among geologist about the age of Damavand volcanism, estimated to be around one million years ago. Developed on the traces of a former eroded platform, with diverse units ranging from Cambrian to Quaternary, the current platform of this volcano comprises of volcano-sedimentary sequences (AliKahi, 2014).

The western part of this zone is NW-SE trending running parallel to Zagros thrust belt; however, the eastern part is a SE$\mathrm{NE}$ trending basin. The conjunction the former and latter zones coincides with Damavand main volcano (Assereto, 1966).

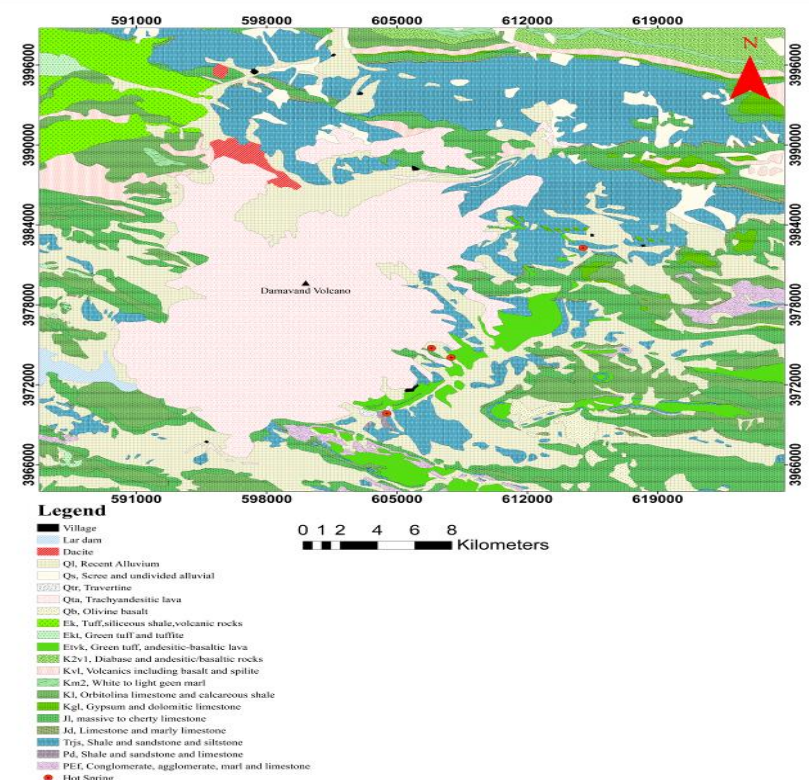

Figure 1. Geological map of Damavand volcano (digitized, compiled and simplified from1/100000 maps of Baladeh, Amol and East Tehran (geological survey of Iran)

\footnotetext{
* Corresponding author
} 


\section{METHODS}

Targeting of geothermal resources of is a multi-step process that can be facilitated by a GIS system, in which favourable zones are gradually shrunk. Prior to this process, however, a thorough evaluation of geological, Hot Springs, and geophysical, and satellite imaginary data is required, on which we will elaborate here.

\subsection{Geology}

Geological studies are used in the processing, interpretation and identification of the potential and development of geothermal reservoirs, whose important features are the younger igneous bodies belonging to the Quaternary, the younger volcanic rocks, travertine sedimentary rocks, the genus and age of the rock units of the region.

Generally, quaternary volcanic Rocks and travertine sedimentary units are the major units of the study area. Erupted through faults systems, volcanic units are inextricably intertwined with hot springs of the area. In this study, the geological units were extracted from 1:100,000 geological map of the study. Distances to quaternary volcanic and travertine units were calculated, from which binary maps were generated; distances below $3000 \mathrm{~m}$ and $4000 \mathrm{~m}$ from quaternary volcanic and travertine units were respectively considered as evidence layers for targeting geothermal resources (Figure 2).
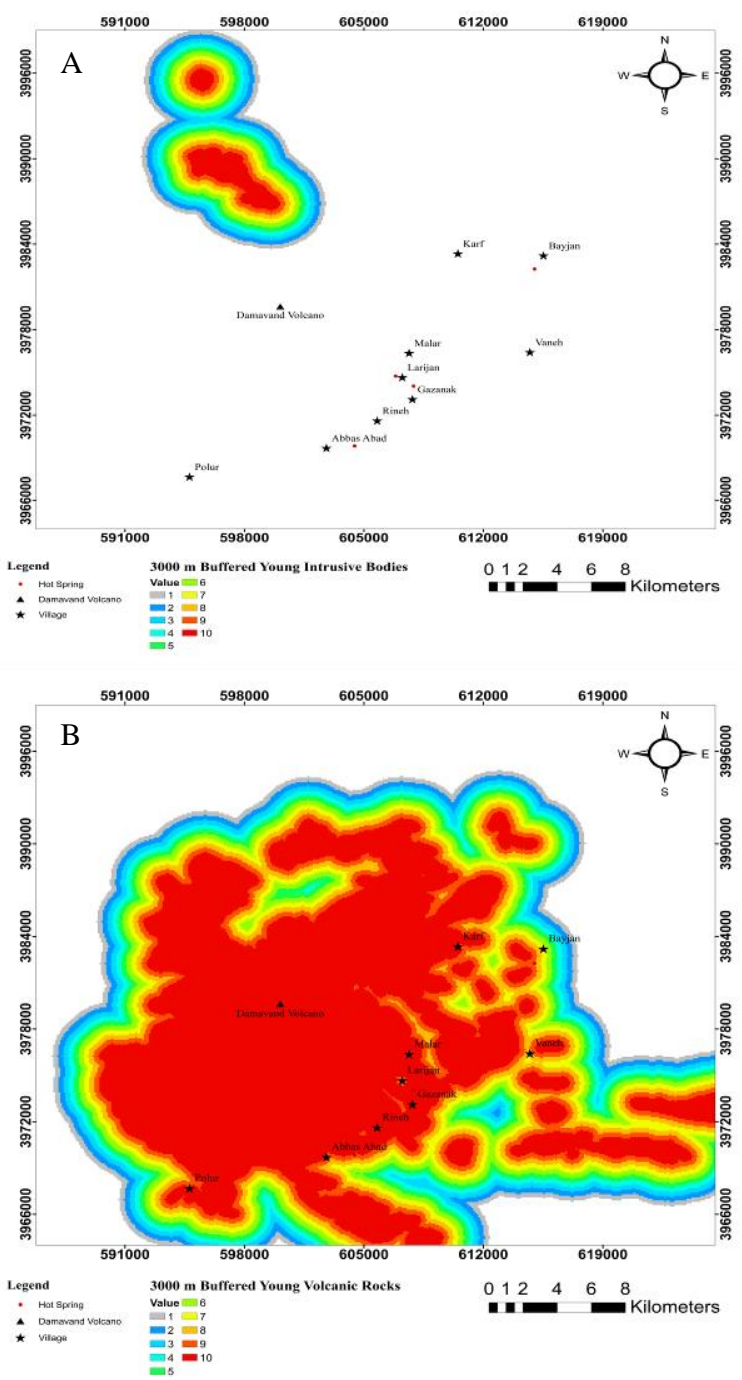
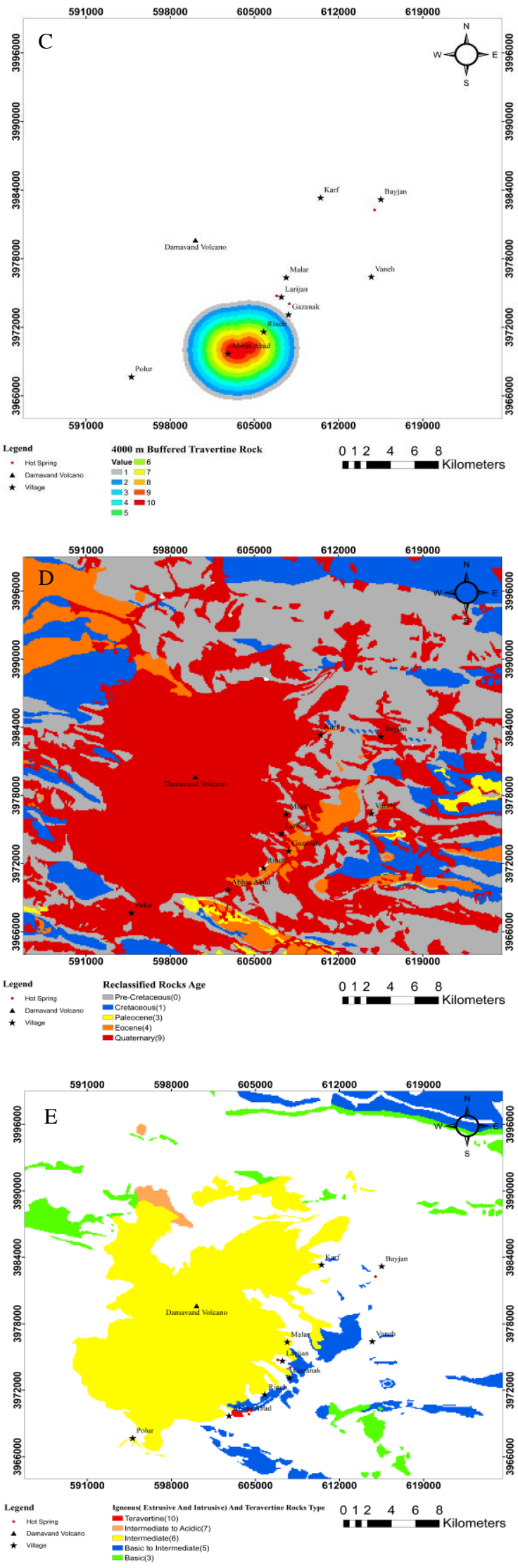

Figure 2. Geology Factor Classified map A) Young intrusive bodies. B) Young volcanic rocks. C) Travertine sedimentary rock. D) Distribution Rocks based on age. E) Distribution rocks based on type 


\subsection{Geophysics}

Geophysical studies can be beneficial for the recognition of geothermal sources. Exploration of geothermal resources without geophysical studies has high costs and misleading results. Geothermal sources are located on active tectonic areas and activities of intrusive and extrusive igneous masses reflecting distinct geomagnetic signals. Therefore, the lateral distribution of intrusive bodies and faults can be somewhat interpreted using geomagnetic data (Norollahi et al, 1998).

To interpret geomagnetic data, numerous filters should be applied. Perhaps the most crucial filter is the reduction to pole (RTP) filter that require inclination and azimuth of data (Figure 3). Analytical signal, an edge enhancement filter, is a second filter that is useful for the boundary and edge detection of magnetic bodies (Figure 3 ).

Heat flux is also an important parameter in the exploration geothermal resources, which was determined by geophysical data and classified in ten categories for being used in further stages (Figure 3) (Arkani, 1990).
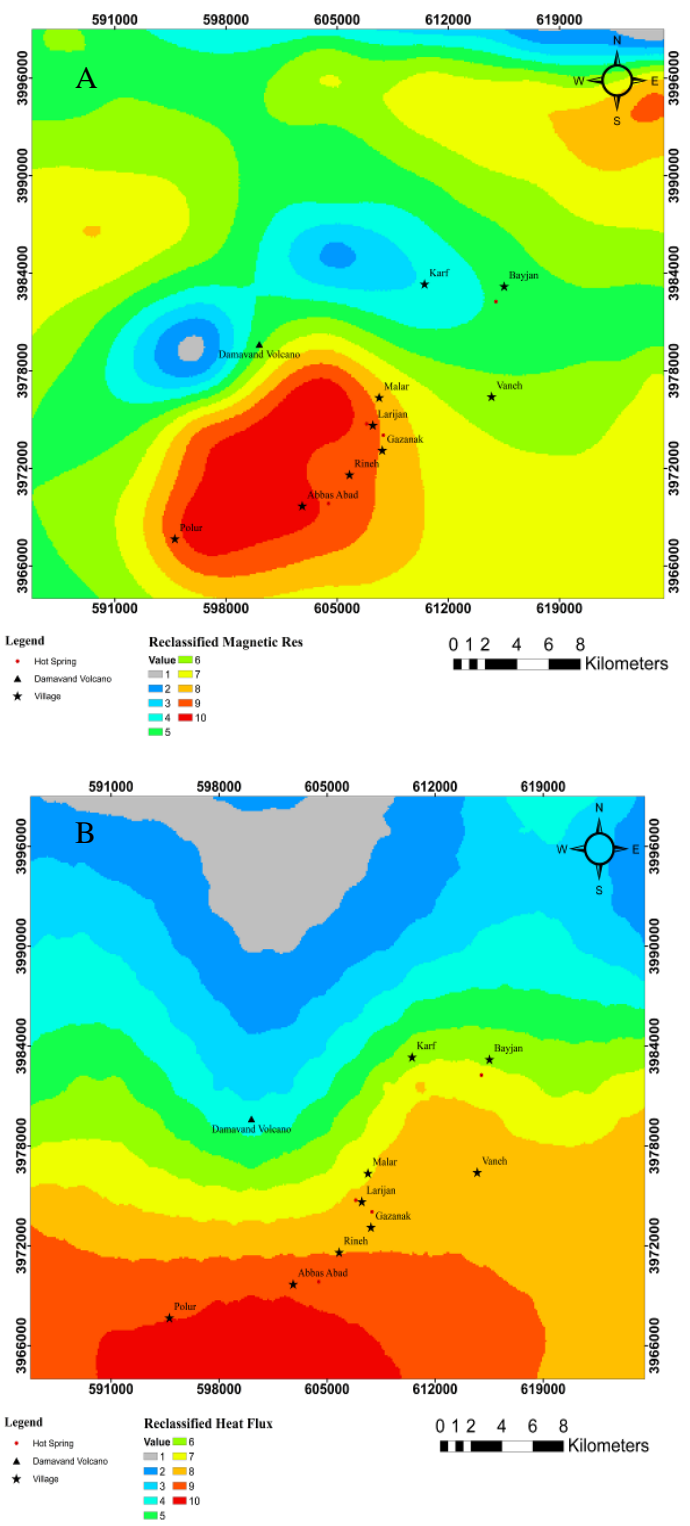

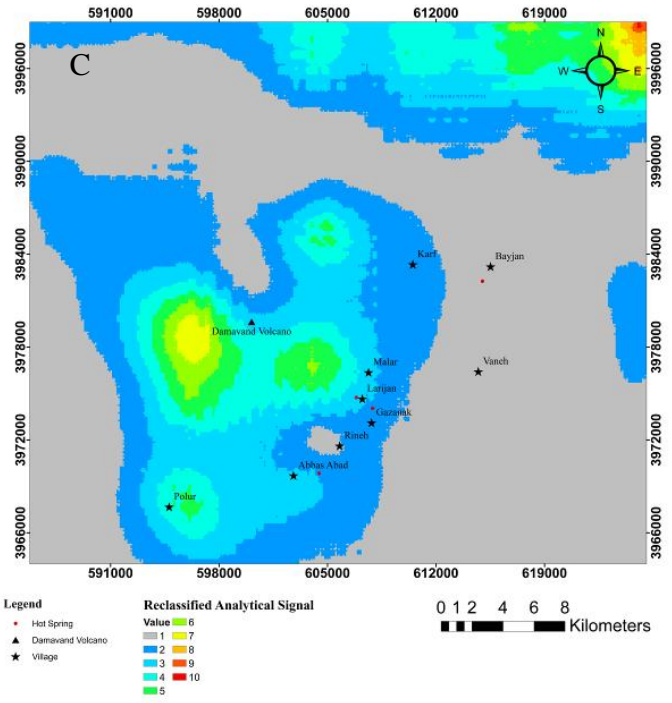

Figure 3. Geophysical Factor Classified map A) RTP map. B) Heat Flux map. C) Analytical Signal map

\subsection{Hot Springs}

Hot springs are regarded as active geothermal zones. The distances from these points were calculated, and a map of distances below $4000 \mathrm{~m}$ from these points was considered as an evidence layer for targeting geothermal resources (Figure 4).

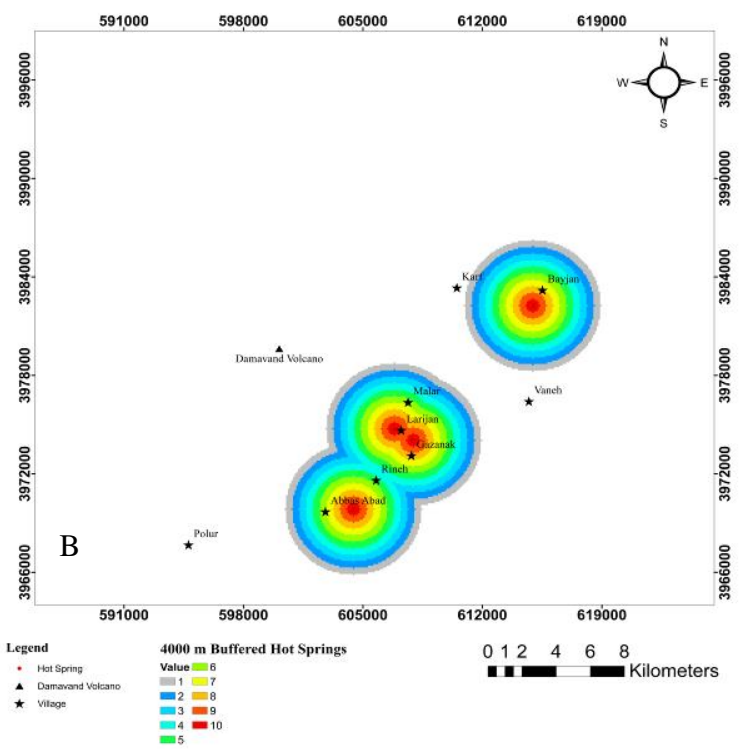

Figure 4. Hot Springs Factor Classified map, after 4000 m buffering

\subsection{Remote Sensing}

Remote sensing can detect geological and alteration features. Hydrothermal alterations were recognized by the processing of ASTER data. Band ratio, principle component analysis, and selective component analysis (Crosta's approach) were in this regard. Argillic, phyllic, propylitic, silicic alterations and iron oxide affected zones were extracted and then merged together to be used as a layer for further analysis (Figure 5).

The temperature of earth's surface was recognized by the processing of ASTER data captured at night, which is on the basis Black Knight satellite conspiracy theory, Planck theory, and the reflection of electromagnetic waves. A map of distances 
below 3000m From Anomaly Temperature (After calculated mean and std-deviation $(\mu+2 \sigma))$ was considered as an evidence layer for targeting geothermal resources (Figure 5).
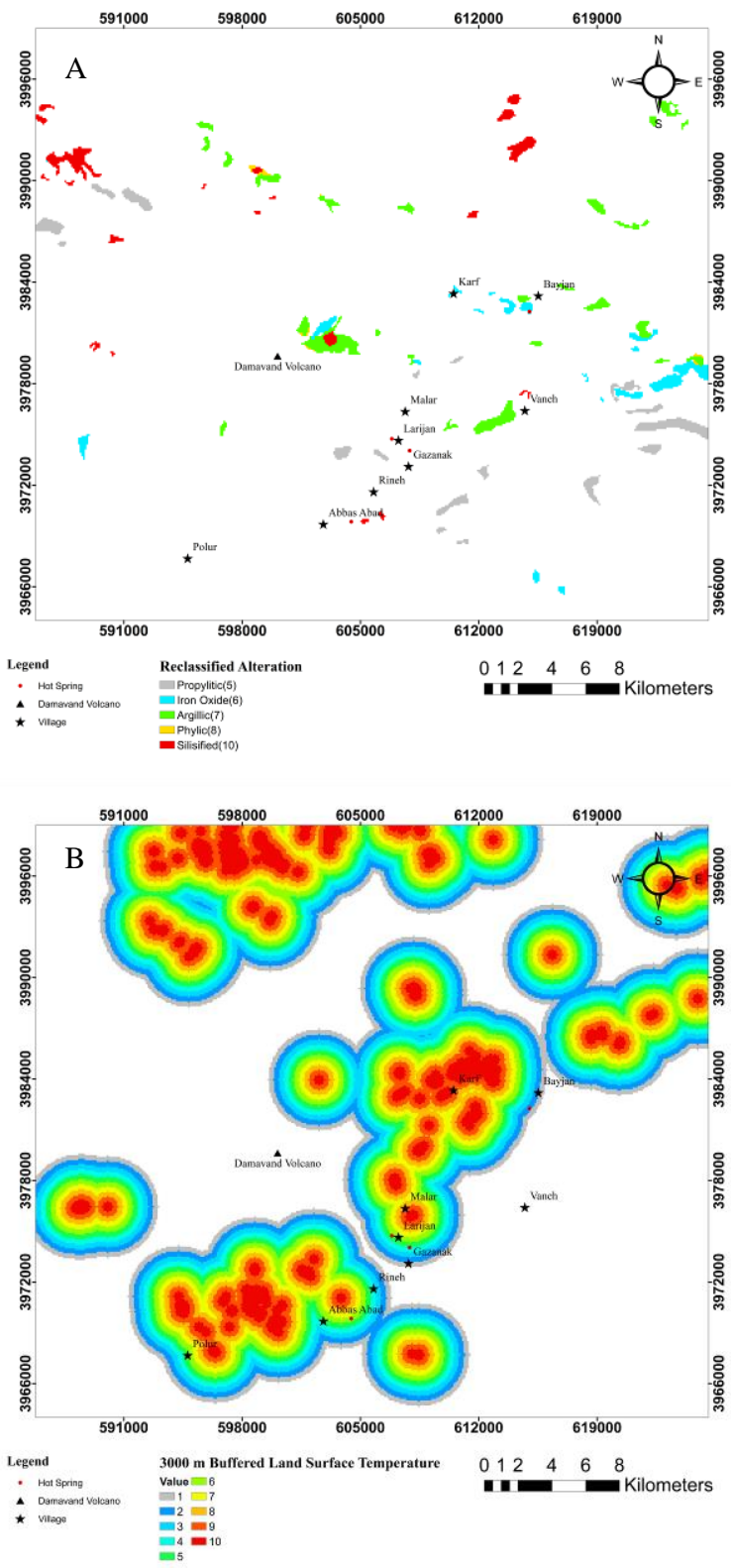

Figure 5. Remote Sensing Factor Classified map A) The alteration distribution obtained from ASTER images. B) The Land Surface Temperature after extract anomaly points and 3000 m buffering

\subsection{Structural features}

Faults and fractures act as corridors for the transportation of hydrothermal fluids, and thus play a pivotal rule in the exploration of geothermal resources. The faults were extracted from the 1:100,000 geological map of the study area, and were merged by those recognized by geophysical data. A binary map showing the distances below $6000 \mathrm{~m}$ from these faults were generated and used as an evidence layer. The faults density map was also introduced as a evidence layer of structural factor component (Figure 6).
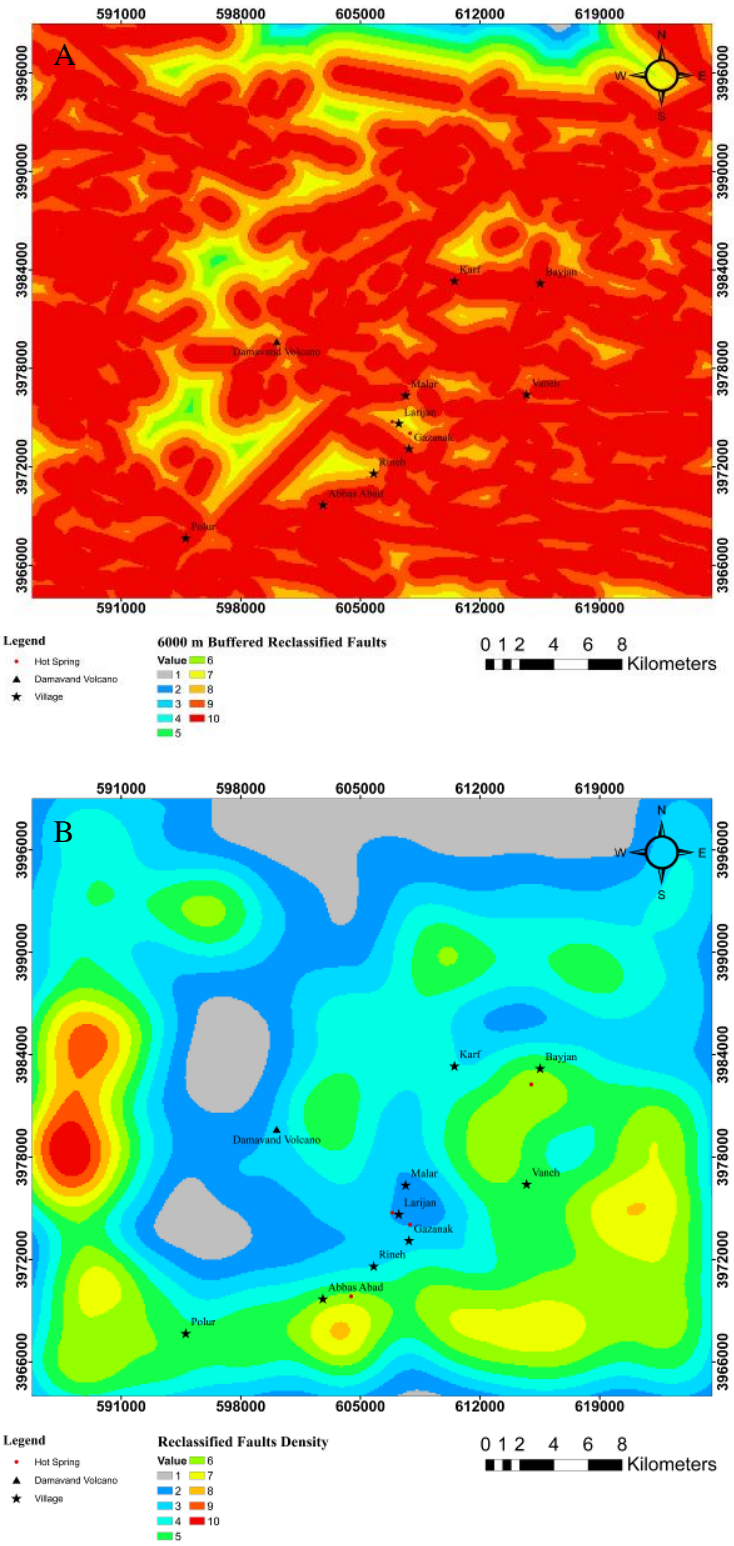

Figure 6. Structural Factor Classified map A) Distribution of the faults after $6000 \mathrm{~m}$ buffering. B) Faults density in study area

\section{INTEGRATION OF EVIDENCE LAYERS}

There are data- and knowledge-driven methods for the integration of evidence layers. While the former techniques suit data-rich zones, and thus can be applied for detailed surveys, the latter is appropriate for preliminary exploration surveys (Bonham-Carter, 1994). In this study, we employed two knowledge-driven techniques, namely cumulative overlay and weighted index overlay.

\subsection{Cumulative Overlay}

As depicted in the Figure 7, in this method, the evidence layers are classified in 10 categories, and then ranked in consecutive numbers from 1 to 10 , with 10 to be accounted as the most important criterion. The layers are then superimposed by one another, and the values of pixels are added to one another. The result of this integration method showing in the Figure 8. 


\begin{tabular}{|l|l|l|l|}
\hline 2 & 5 & 2 & 1 \\
\hline 1 & 5 & 1 & 2 \\
\hline 2 & 4 & 3 & 3 \\
\hline
\end{tabular}$+$\begin{tabular}{|l|l|l|l|}
\hline 6 & 4 & 2 & 5 \\
\hline 3 & 3 & 2 & 2 \\
\hline 1 & 5 & 1 & 3 \\
\hline
\end{tabular}$=$\begin{tabular}{|l|l|l|l|}
\hline 8 & 9 & 4 & 6 \\
\hline 4 & 8 & 3 & 4 \\
\hline 3 & 9 & 4 & 6 \\
\hline
\end{tabular}

Figure 7. Combination of evidence layers by multi-class cumulative overlay with two input layers
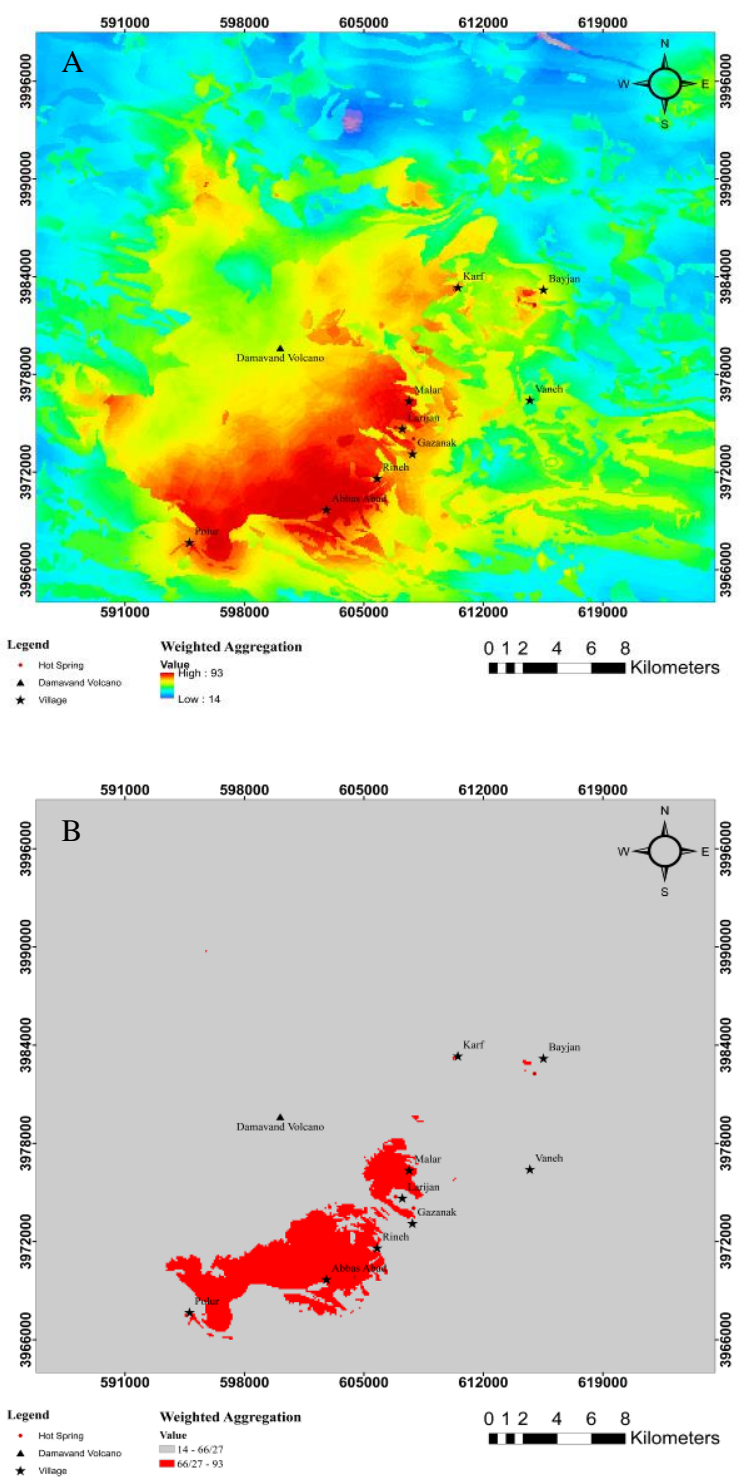

Figure 8. A) The result of cumulative overlay. B) The result of cumulative overlay after applying $(\mathrm{m}+2 \sigma)$

\subsection{Weighted Index Overlay}

In this model, not only are the evidence layers classified, but the layers themselves are individually ranked and prioritized (Keynejad, 2011) Expert's opinions are used to rank the layers, and in this study, we employed the analytical hierarchical process/fuzzy (FAHP) to do so. The weights, in a range of 0 to 1 , are calculated, as it can be seen in table 1 .
Table 1. Expert weights obtained by the Fuzzy/Ahp method

\begin{tabular}{|c|c|c|}
\hline Weights & Layer Name & Number \\
\hline 0.4 & Young Igneous Bodies & 1 \\
\hline 0.35 & Young Volcanic Rocks & 2 \\
\hline 0.22 & Travertine Rock & 3 \\
\hline 0.02 & Rocks Type & 4 \\
\hline 0.01 & Rocks Age & 5 \\
\hline 0.61 & RTP & 1 \\
\hline 0.37 & Heat Flux & 2 \\
\hline 0.02 & Analytical Signal & 3 \\
\hline 1 & Hot Spring & 1 \\
\hline 0.98 & Alteration & 1 \\
\hline 0.02 & Land Surface Temperature & 2 \\
\hline 0.96 & Fault Buffer & 3 \\
\hline 0.04 & Fault Density & 4 \\
\hline 0.36 & Geology Factor & 1 \\
\hline 0.33 & Geophysical Factor & 2 \\
\hline 0.25 & Hot Springs Factor & 3 \\
\hline 0.02 & Remote Sensing Factor & 4 \\
\hline 0.02 & Structural Factor & 5 \\
\hline
\end{tabular}

Similar to the previous model, the layers are then superimposed by one another, and the values of pixels are added to one another.

In this study, we commenced by the classification of evidence layers in 10 classes. Then, the weights assigned to layers by the AHP process were multiplied by those of classes. Next, according, our final model was derived (Figure 9). According to the table 1 , geological factor is the most important factor in this model.

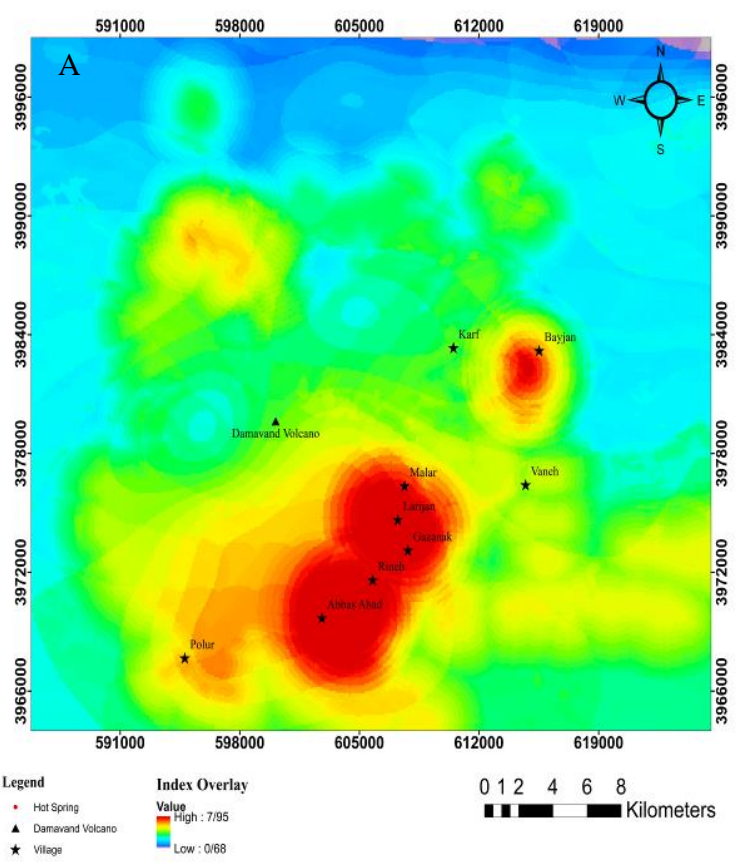




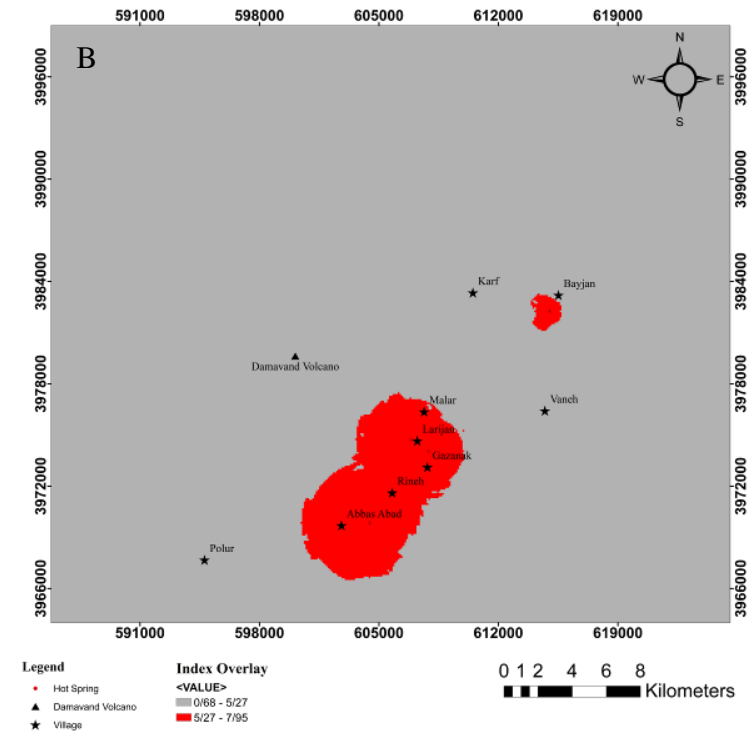

Figure 9. A) The result of Index overlay. B) The result of Index Overlay after applying $(\mu+2 \sigma)$

\section{VALIDATION RESULTS}

There are different methods for validation the results. The most practical ones is the method of statistical matching of the results with ground evidence. In this study, after merging the result of the two methods together, the results of drilling conducted by the Enel Company were used to control and verify the results of the integration. Of the 29 boreholes drilled in the whole area, 16 exploratory boreholes have been located in the study area. After drilling, measurements of thermal flux and thermal gradient have been performed in each drilling borehole. In Figures 10 and 11 , it is possible to observe the location of prioritized areas with the results of drilling.

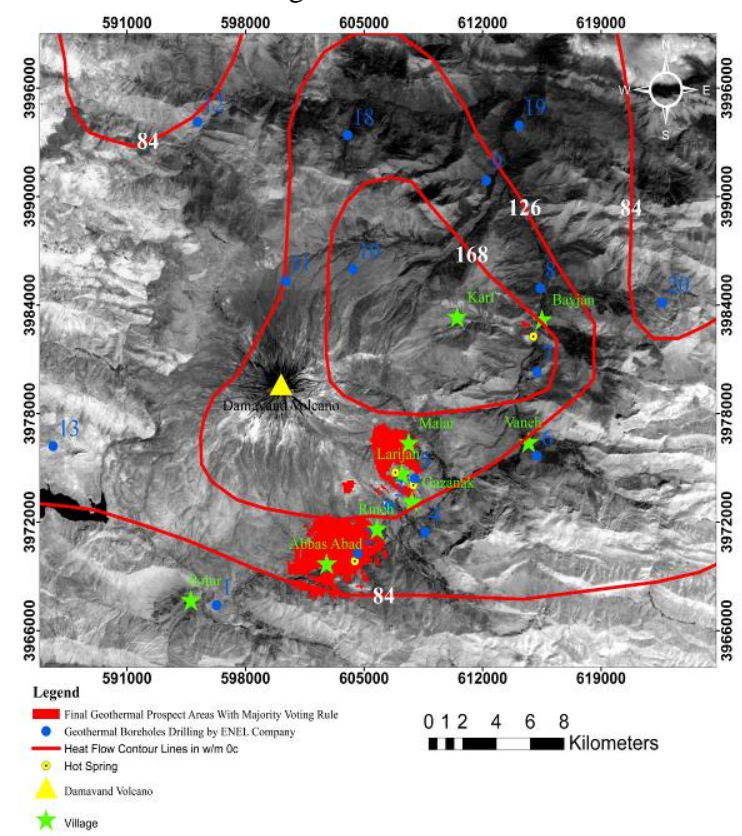

Figure 10. Comparison of final potential regions with thermal flux from the drilling.

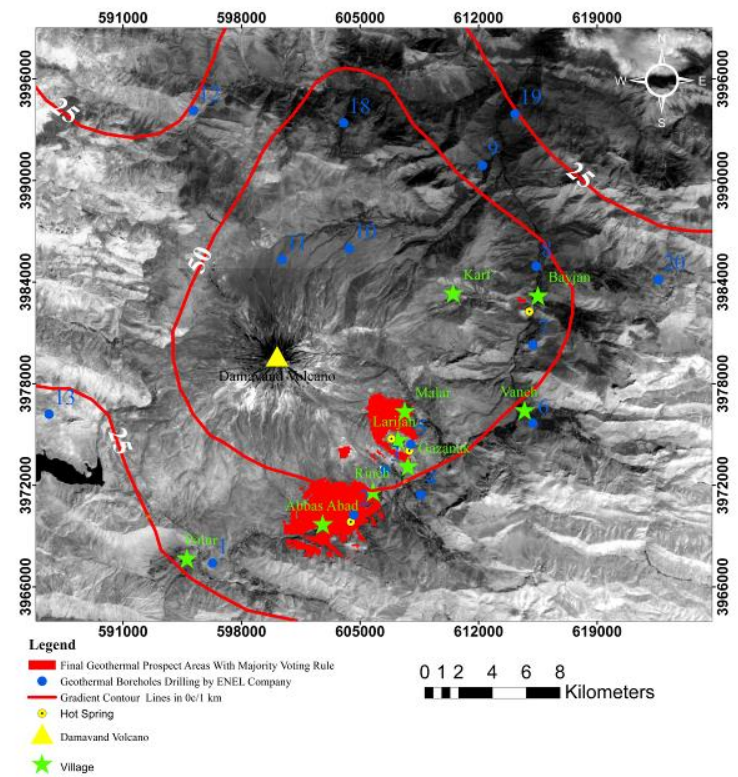

Figure 11. Comparison of final potential regions with thermal gradient from the drilling.

Given that the drillings performed have a mean depth of $100 \mathrm{~m}$ and temperature variations at this depth are not high, the results of measuring the thermal flux of the boreholes are less reliable than the results of thermal flux from the magnetic data. However, comparing the results of integrated and prioritized areas with drilling results indicates the accuracy and precision of the results. It should be noted that the areas with the potential obtained in this research as well as the results of drilling, have high correlation with hot springs and travertine deposits as direct evidence of geothermal sources. According to Figures 10 and 11 , regions with geothermal potential are located in a region with high value thermal flux and thermal gradient. The main objective of the initial exploration is to reduce the size of the study area. In this study, from the area of $1400 \mathrm{~km}^{2}$ of the entire area, four high potential areas have identified with a priority of $0.14,0.38,15.59$, and $6.29 \mathrm{~km}^{2}$, respectively.

\section{CONCLUSIONS}

According to geophysical studies of the area, the largest magnetic field is from the vicinity of the village of polur to malar, and also the thermal flux in the southern peak of Damavand has the highest amount, both of which correspond to the volcanic rock volumes belonging to the Cenozoic period as well as the travertine outcrops of the region. The results of thermal flux from geophysical data indicate that it increases from north to south of the region, and also the location of travertine rock outcrops with areas of thermal flux and high surface temperature and hot springs. Remote sensing studies highlighted the close relationship of volcanic units and alterations, and their partial correlation with high temperature zones, which are, themselves, closely linked with hot springs. Heat flux increases from north to south. The outcrop of travertine rocks is correlated with high-temperature zones.

The area occupied by favourable targets has shrunk by 0.045 and 0.043 percent, respectively by weighted index overlay and cumulative overlay methods. The results of two methods are highly correlated with one another, although the results of the weighted index overlay are more promising. Southern and eastern parts of the Damavand area is highlighted by both methods as potential areas, which should be clearly assessed in 
detailed exploration surveys. The delineated zones are correlated with the locations of hot springs, as well. On the basis of verifications, the potential areas in this study are overlapping with the results of the company's drilling, so that all four priority areas in the regions with flux and thermal gradients are higher than normal

\section{REFERENCES}

Alikahi, M., 2014. Petrogenesis and distribution of young pyroclastic deposits in east Damavand volcano. M. S. thesis, Hormozgan University.

Arkani, H., Urquhart. W.E.S., 1990. Reduction to pole of the north American magnetic anomalie. Geophysics, 55 (2), pp.218225.

Assereto, R., 1966. Geological map of upper Djajrud and Lar valleys (central Elburz, Iran). Ins. Geol.Univ. Milano, Serie G, Publ. 323, 86.

Bahari, R.A., Abbaspour, R.A., Pahlavani, P., 2014, November. Prediction of PM2.5 concentrations using temperature inversion effects based on an artificial neural network. In The ISPRS international conference of Geospatial information research (Vol. 15, p. 17).

Bigdeli, B., Samadzadegan, F., Reinartz, P., 2013. Classifier fusion of hyperspectral and lidar remote sensing data for improvement of land cover classifcation. International Archives of the Photogrammetry, Remote Sensing and Spatial Information Sciences, 1, p.W3.

Bonham-Carter, G.F., 1994. Geographic Information Systems for Geoscientists: Modelling with GIS, Pergamon Press, Ontario, 398 p.

Davidson, J., Hassanzadeh, J., Berzins, R., Stockli, D.F., Bashukooh, B., Turrin, B., Pandamouz, A., 2004. The geology of Damavand volcano, Alborz Mountains, northern Iran. Geol. Soc. Am. Bull.116 (1-2), 16-29.

Delavar, M.R., Samadzadegan, F., Pahlavani, P., 2004. A GISAssisted optimal urban route finding approach based on genetic algorithms. International archives of photogrammetry remote sensing and spatial information sciences, 35(Part 2), pp.305308.

Keynejad, S., 2011. Evaluating Geothermal Potential in East Azerbaijan Province Using Geologic and Exploration Data. M.S. thesis, Isfahan University.

Macleod, I., N., Jones, k., Fan Dai, T., 1994. 3-D Analytic signal in the interpretation of total magnetic field data at low magnetic latitudes. Exploration Geophysics, 679-688.

Nouraliee, J., Porkhial, S., Tamjidi, A., 2010. Reevalution of geothermal energy potential in Damavand region. World geothermal congress, Indonesia, 25-59 April.

Noorollahi, Y., Jamaleddini, M., Ghazban, F., 1998. Iran Geothermal Energy Potentiometric Project, Investigating the geothermal energy potentials in the world. New Energy Organization of Iran, Geological Survey, Tehran.
Pahlavani, P., Samadzadegan, F., Delavar, M.R., 2006, September. A GIS-based approach for urban multi-criteria quasi optimized route guidance by considering unspecified site satisfaction. In International Conference on Geographic Information Science (pp. 287-303). Springer, Berlin, Heidelberg.

Pahlavani, P., Sheikhian, H., Bigdeli, B., 2017. Assessment of an air pollution monitoring network to generate urban air pollution maps using Shannon information index, fuzzy overlay, and Dempster-Shafer theory, A case study: Tehran, Iran. Atmospheric environment, 167, 254-269.

Yousefi, H., Noorollahi, Y., Ehara, S., Itoi, R., Yousefisahzbi, A., Fujimitsu, Y., Nishijima, J., Sasaki, K., 2010. Developing the geothermal resources map of Iran. Geothermics 39, Volume 39, Issue Number 2, 140-151. 